\title{
EDITORIAL
}

\section{Childhood cancer studies in West Germany: The first 10 years}

\author{
F. Lampert
}

The concept of treating all children with newly diagnosed malignancies in a prospective uniform manner suitable for later analysis has become an established custom in the Federal Republic of Germany. It all started about 11 years ago when children with acute lymphoblastic leukemia began to be treated uniformly by cranial irradiation and simple but effective combination chemotherapy. Since then, a very disciplined and effective cooperation has been achieved in other areas of pediatric oncology as well. Protocols with increasingly intensive combination chemotherapy have evolved. A summary of the results of the larger therapeutic studies is presented in Table 1.

It is only by analysing large numbers of patients treated in the same way that results and new insights can be achieved which can stand the test of time and be internationally recognized.

During these past 10 years, every pediatric oncologist in our country - whether based at a city hospital or at a large university centre - has contributed a lot of individual effort, but also has benefited from ,riding in the same boat", and, most rewardingly, has learned a lot. We should go on in this direction - for the benefit of every child.

Tumor therapy is not yet optimal and should be further refined - but it exists and can achieve cures (with the exception of disseminated neuroblastoma).

However, the established therapeutic organisation and cooperation may also be used to facilitate the study of tumor pathogenesis and etiology. Many diversified tissue examinations can be done by sophisticated methods in specialized laboratories within the frame-work of an identically treated collective.

Perhaps pediatrics could thus lead the way not only in the advancement of tumor therapy, but also in the investigation of tumorigenesis.

Table I Results of childhood cancer studies in West Germany

\begin{tabular}{lclcc}
\hline disease & $\begin{array}{c}\text { patients } \\
(n)\end{array}$ & study & $\begin{array}{c}\text { max. obs. time } \\
\text { (years) }\end{array}$ & $\begin{array}{c}\text { disease-free survival } \\
(\%)\end{array}$ \\
\hline ALL & $495(659)$ & DAL 71/74 & $71 / 2(11)$ & 33 \\
ALL & 119 & BFM 70/76 & 12 & 55 \\
ALL & 158 & BFM 76/79 & 6 & 69 \\
AML & 130 & BFM 78 & $31 / 2$ & 41 \\
NHL, I-IV & 116 & BFM 75/81 & 7 & 61 \\
HD, I-IV & 170 & DAL-HD 78 & 4 & 91 \\
OSTEO & 71 & GPO-COSS 77 & 5 & 57 \\
NBL-IV $>1 \mathrm{y}$. & 82 & GPO-NBL 79 & 3 & 10 \\
& 24 & & & 61 \\
\hline
\end{tabular}

$A L L=$ acute lymphoblastic leukemia

AML = acute myelocytic leukemia

NHL = non-Hodgkin-lymphoma

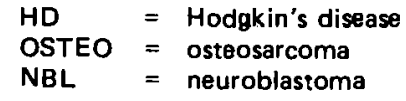

April 1982

Prof. Dr. F. Lampert, Universitäts-Kinderpoliklinik, Feulgenstraße 12, 6300 Gießen 